\title{
CARTAS PARA PEDRO ALMODÓVAR NO ENSINO REMOTO
}

\author{
Bruno César Evangelista Silva ${ }^{1}$
}

\section{RESUMO}

O presente trabalho serviu de recurso para dinamizar as aulas virtuais de língua espanhola e refletir sobre o aprendizado desse idioma no período de pandemia nas Escolas Técnicas Etec Dr. Emílio Hernandez Aguilar e Etec de Mairiporã. Além de exercitar a escrita, a leitura e a comunicação, bem como discutir sobre a formação do docente para esse fim. Como objetivo buscou-se explorar a linguagem cinematográfica, o contato com a cultura e língua espanhola. Além de levar os alunos a melhorarem a interpretação e produção de textos em espanhol, confrontar opiniões e exprimir suas argumentações etc. Recorreu-se a metodologia qualitativa, baseada em revisões bibliográficas e pesquisas ancoradas em filmes e curtas metragens. Como resultados e conclusões os alunos tiveram contato com a língua, cinema e cultura espanhola, além de conhecer sobre as bibliografias dos roteiristas, ampliando, assim, sua bagagem cultural, além de aperfeiçoar a leitura e a escrita nessa língua alvo, através da produção escrita de cartas.

Palavras-chave: Aulas Virtuais; Cultura; Língua Espanhola; Leitura; Escrita.

\section{ABSTRACT}

The present work served as a resource to streamline the virtual classes of Spanish language and reflect on the learning of that language during the pandemic period at the Technical Schools Etec Dr. Emílio Hernandez Aguilar and Etec de Mairiporã. In addition to exercising writing, reading and communication, as well as discussing teacher training for this purpose. The objective was to explore the cinematographic language, the contact with the Spanish culture and language. In addition to leading students to improve the interpretation and production of texts in Spanish, to confront opinions and express their arguments, etc. Qualitative methodology was used, based on bibliographic reviews and research anchored in films and short films. As results and conclusions, the students had contact with the Spanish language, cinema and culture, in addition to knowing about the writers' bibliographies, thus expanding their cultural background, in addition to perfecting reading and writing in that target language, through the written production of letters .

Keywords: Virtuais Classrooms; Culture; Espanhola Language; Read; Written.

\section{RESUMEN}

El trabajo actual sirvió como recurso para impulsar las clases virtuales de español y reflexionar sobre el aprendizaje de este idioma en el período de pandemia en las Escuelas Técnicas Etec Dr. Emílio Hernández Aguilar y Etec de Mairiporã. Además de ejercer la escritura, la lectura y la comunicación, así como discutir la formación del maestro para este propósito. El objetivo era explorar el lenguaje cinematográfico, el contacto con la cultura y la lengua españolas. Además de llevar a los estudiantes a mejorar la interpretación y producción de textos en español, confrontar opiniones y expresar sus argumentos, etc. Se utilizó la metodología cualitativa, basada en revisiones bibliográficas e investigaciones ancladas en películas y cortometrajes. Como resultados y conclusiones, los alumnos tuvieron contacto con la lengua, el cine y la cultura españolas, además de conocer las bibliografías de los escritores, ampliando así su bagaje cultural, además de mejorar la lectura y la escritura en este idioma objetivo, a través de la producción escrita de letras.

Palabras clave: Clases Virtuales; Cultura; Lengua Española; Lectura; Escritura.

${ }^{1}$ Licenciado em Letras (Port-Esp-Ing) e Pedagogia, Especialista em Metodologia do Ensino de Espanhol, Língua Portuguesa e Literatura. E-mail: brumnocesar@gmail.com. 


\section{INTRODUÇÃO}

Em virtude da suspensão das aulas e isolamento social por conta da pandemia do COVID-19, os professores, em um curto prazo, se viram obrigados a mudar os seus métodos e práticas de ensino no ano de 2020.

Um dos maiores desafios no ensino de língua espanhola na Etec de Mairiporã e na Etec Dr. Emílio Hernandez Aguilar foi o de transformar o modelo presencial ao modelo de educação virtual para garantir a continuidade da aprendizagem dos alunos nas escolas técnicas.

Apesar de ser uma fase difícil, essa mudança repentina trouxe um aprendizado tanto para os alunos quanto para os professores. Os dois primeiros meses foram de adaptação e para que nenhum aluno fosse prejudicado o Centro Paula Souza distribuiu para as Etecs e Fatecs chipes de acesso à internet.

Com o intuito de estimular as aulas de espanhol e amenizar o sofrimento causado pelo isolamento social, realizou-se uma proposta de atividade que promovesse a cultura e a arte, visto que trabalhar com elas ajuda a diminuir os sentimentos negativos e deixar a aula prazerosa, e também, desenvolver nos educandos do ensino médio de forma interdisciplinar, um exercício que despertasse a sua criatividade e valorização de gêneros, tais como: textos, biografia, carta, revistas, diálogos, filmes, documentários, curta metragem, artigos etc, explorando o idioma espanhol em sua totalidade.

O projeto teve como objetivo estimular o interesse dos alunos, explorando a linguagem cinematográfica das obras do cineasta Pedro Almodóvar, visto que os filmes são em língua espanhola e possuem um imenso potencial de aproveitamento no processo educativo, pois apresentam ampla capacidade de comunicação e muitas vezes, abordam temas que são mais bem compreendidos que uma aula expositiva. Além de ajudar os alunos a reconhecerem a importância de conhecer novas culturas como recurso estratégico para se aprender outra língua, melhorar a interpretação e produção de textos em espanhol, confrontar opiniões e pontos de vistas diferentes, argumentar na defesa de suas ideias, pesquisar e sistematizar informações relevantes para a compreensão e resolução de problemas. Após análise e discussão, a maioria dos alunos escolheu desenvolver a produção de escrita de carta e, em grupos, 
pesquisaram diferentes modelos desse gênero que posteriormente apresentaram para suas respectivas turmas.

Para a produção, foi explorado, em espanhol, as partes e a estrutura da carta como: data (cabeçalho), saudação ao destinatário, assunto, saudação de despedida e nome do remetente, e por decisão do professor, foi definido que cada aluno escolheria um colega de sua turma para ser o seu destinatário.

\section{MATERIAIS E MÉTODOS}

Foi proposto para três turmas de $2^{0}$ ano do ensino médio e para duas turmas de $2^{\circ}$ ano de ensino médio e técnico, que realizassem pesquisas sobre filmes espanhóis, pontos turísticos e manifestações culturais na Espanha. Após as investigações o docente selecionou trechos de alguns filmes espanhóis para que os alunos decidissem quais Ihes chamaram mais a atenção pelo enredo, fotografias e elementos artísticos. Depois de discutirem, e por decisão da maioria das turmas, optaram pelo diretor Pedro Almodóvar, por apresentar um estilo de longa-metragem complexo, diferente do que eles já conheciam, e pelas cores primarias e intensas.

Das sinopses e trailers de filmes pesquisados pelos alunos, os que mais Ihes chamaram a atenção foram: Todo sobre mi madre; Tacones Lejanos; Volver; Los amantes pasajeros; Mujeres al borde de un ataque de nervios e Dolor y gloria. A região escolhida para mencionarem na carta foi a cidade de Barcelona por ser conhecida pela sua arte, arquitetura, museus, monumentos modernistas e sítios arqueológicos romanos.

Essas atividades foram desenvolvida no período de um mês no $4^{\circ}$ bimestre de 2020.

Atividades propostas foram:

$\checkmark$ Ler a instrução do projeto;

$\checkmark$ Leitura de material produzido pelo professor

$\checkmark$ Pesquisar pontos turísticos da Espanha;

$\checkmark$ Assistir aos vídeos propostos pelo professor;

$\checkmark$ Escrever a carta em espanhol;

$\checkmark$ Fazer uma releitura de uma cena dos filmes de Pedro Almodóvar; 


\section{METODOLOGIA}

$\checkmark$ Aula virtual;

$\checkmark$ Utilização dos recursos da plataforma Microsoft Teams, para aplicação dos procedimentos descritos;

$\checkmark$ Produção textual;

$\checkmark$ Links de trailers e do Youtube disponíveis na plataforma Microsoft Teams;

$\checkmark$ Interação com os alunos pelo chat;

\section{PROPOSTA DE TRABALHO PELA PLATAFORMA TEAMS - RESULTADO E DISCUSSÕES}

Para trabalhar a escrita individual, os alunos receberam um material cedido pelo professor com diferentes gêneros textuais, em espanhol, com o intuito de ampliar o repertório dos educandos e ajudar a decidirem qual o gênero que gostariam de trabalhar. Após análise e discussão, a maioria dos alunos escolheu desenvolver a produção de escrita de carta e, em grupos, pesquisaram diferentes modelos desse gênero que posteriormente apresentaram para suas respectivas turmas.

Para a produção, foi explorado, em espanhol, as partes e a estrutura da carta como: data (cabeçalho), saudação ao destinatário, assunto, saudação de despedida e nome do remetente, e por decisão do professor, foi definido que cada aluno escolheria um colega de sua turma para ser o seu destinatário. 


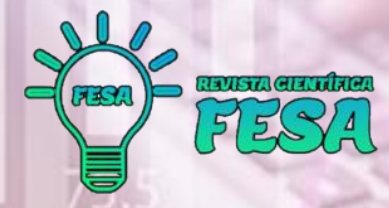

Mai. 2021

v. 1, n. $4,124-135$

ISSN: $2676-0428$

Imagem 1. Carta escrita pelo anulo O. P de O. M.

Barcelona, 17 de noviembre 2020

\section{Querida Skye:}

¡Traigo noticias de Barcelona! Gané un lugar en el concurso de fotografía inspirado en las películas de Pedro Almodóvar, famoso director español que dirigió algunas producciones como "Dolor y Gloria", "Hable con Ella", "La Flor de Mi Secreto" y "Los amantes pasajeros”. ¡Estoy muy emocionado y esperanzado por mi participación en esta competencia!

¡Barcelona es una ciudad increíble! Además de muchos centros comerciales, industrias y universidades, ¡está llena de cultura! ¡Una hermosa cultura! Museos, galerías, obras de arte... ¡además del espectáculo de la naturaleza que lo rodea! El deporte entonces.. ¡muy tradicional y encantador!

¡Hasta ahora, visité algunos puntos turísticos para enamorarme! El Arco de Triunfo, el Museo Nacional de Arte de Catalunya, la Torre de Montjuïc y el museo del fútbol: Camp Nou. ¡Y para mejorar todo, los catalanes son muy amables y vibrantes!

¡Tráeme noticias de Pensilvania! Tengo que irme ahora, ¡tengo una cita importante!

Con afecto,

Otavio.

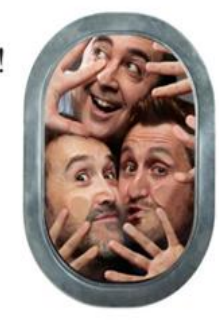

Fonte: Fotografias do autor.

Os estudantes pesquisaram a biografia de Pedro Almodóvar e assistiram alguns trailers de suas obras, mas, visto que alguns filmes do diretor têm a classificação indicativa não recomendada para menores de 16 anos, para 0 desenvolvimento da atividade de releitura, foi selecionado pelo docente algumas imagens e apresentadas para as turmas em arquivo Powerpoint com a instrução de que os alunos as usassem como referência para fazerem a criação de uma nova obra fotográfica. 
Imagem 2. Carta do aluno O. P de O. M.

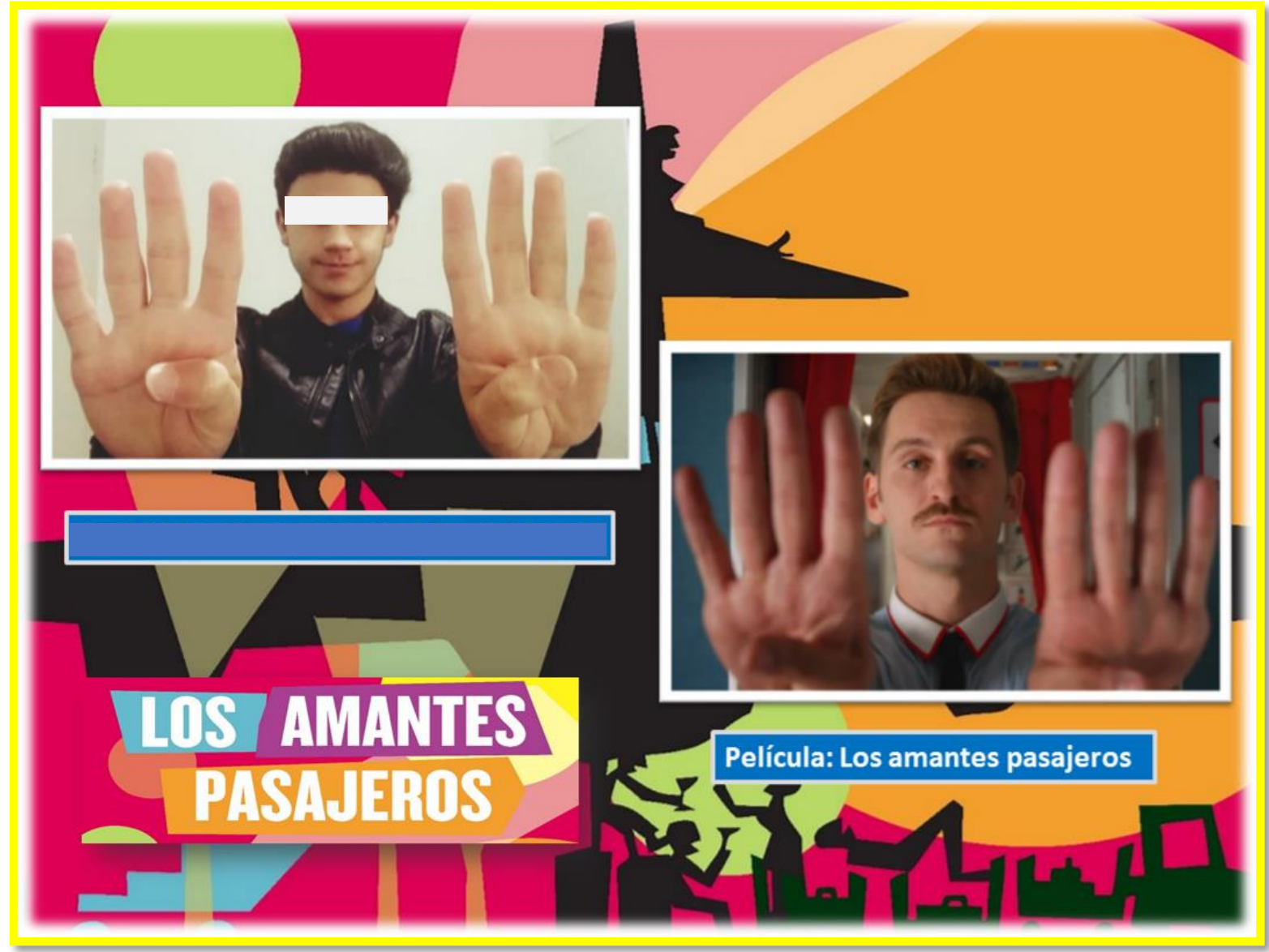

Fonte: Releitura do ator Raúl Arévalo.

Além de avaliar e dar menção pelo trabalho feito, com o intuito de incentivar e aumentar o interesse na atividade, foi criado pelo professor um certificado de menção honrosa com imagens do diretor retiradas do site de busca google para os alunos que se destacassem na atividade. 


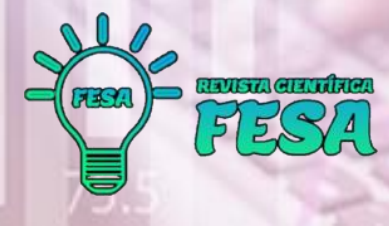

Mai. 2021

v. 1, n. $4,124-135$

ISSN: $2676-0428$

Imagem 3. Carta da aluna J. S. P.

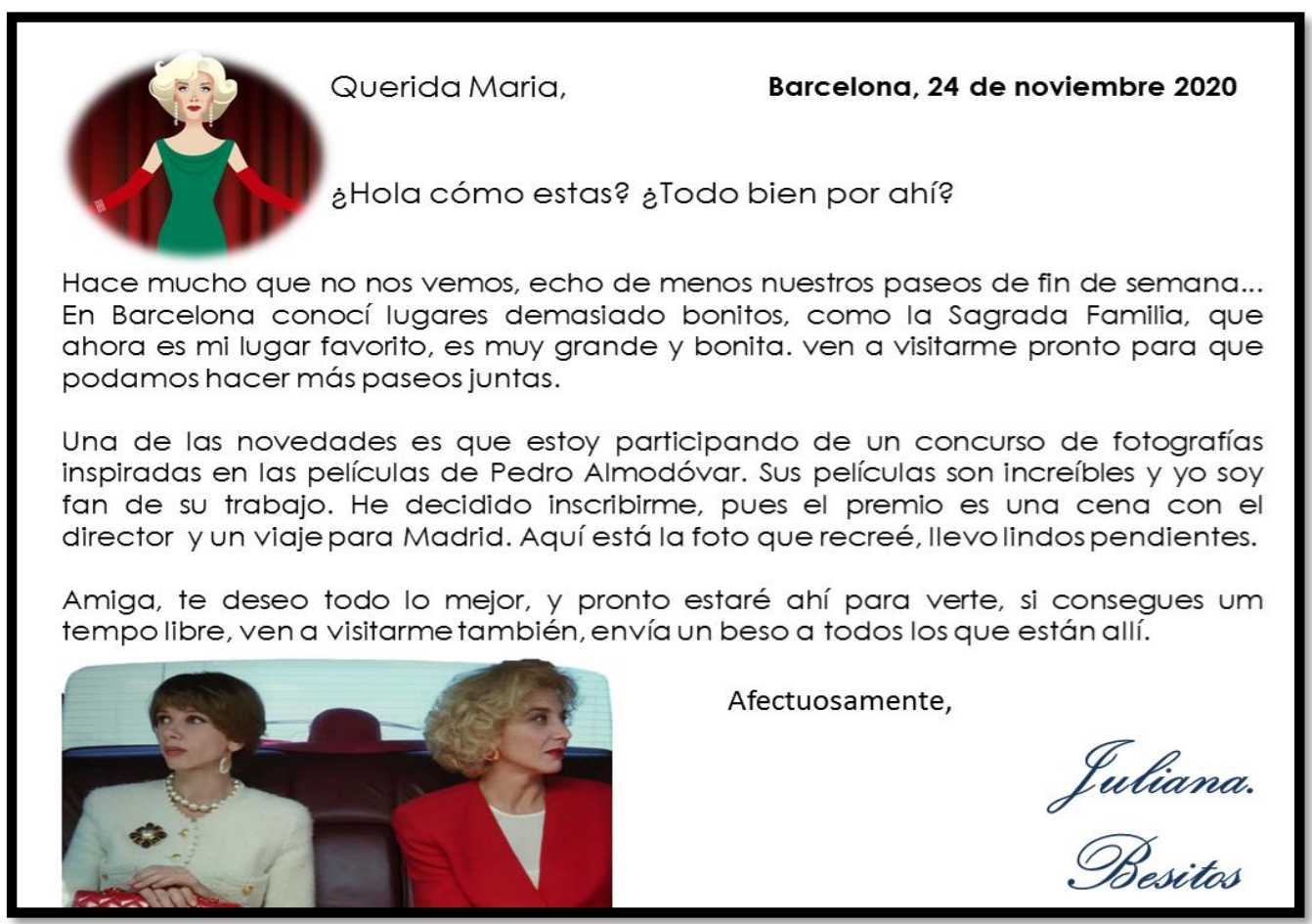

Fonte: Releitura da atriz Marisa Paredes.

Imagem 4. Fotografias e montagem da aluna

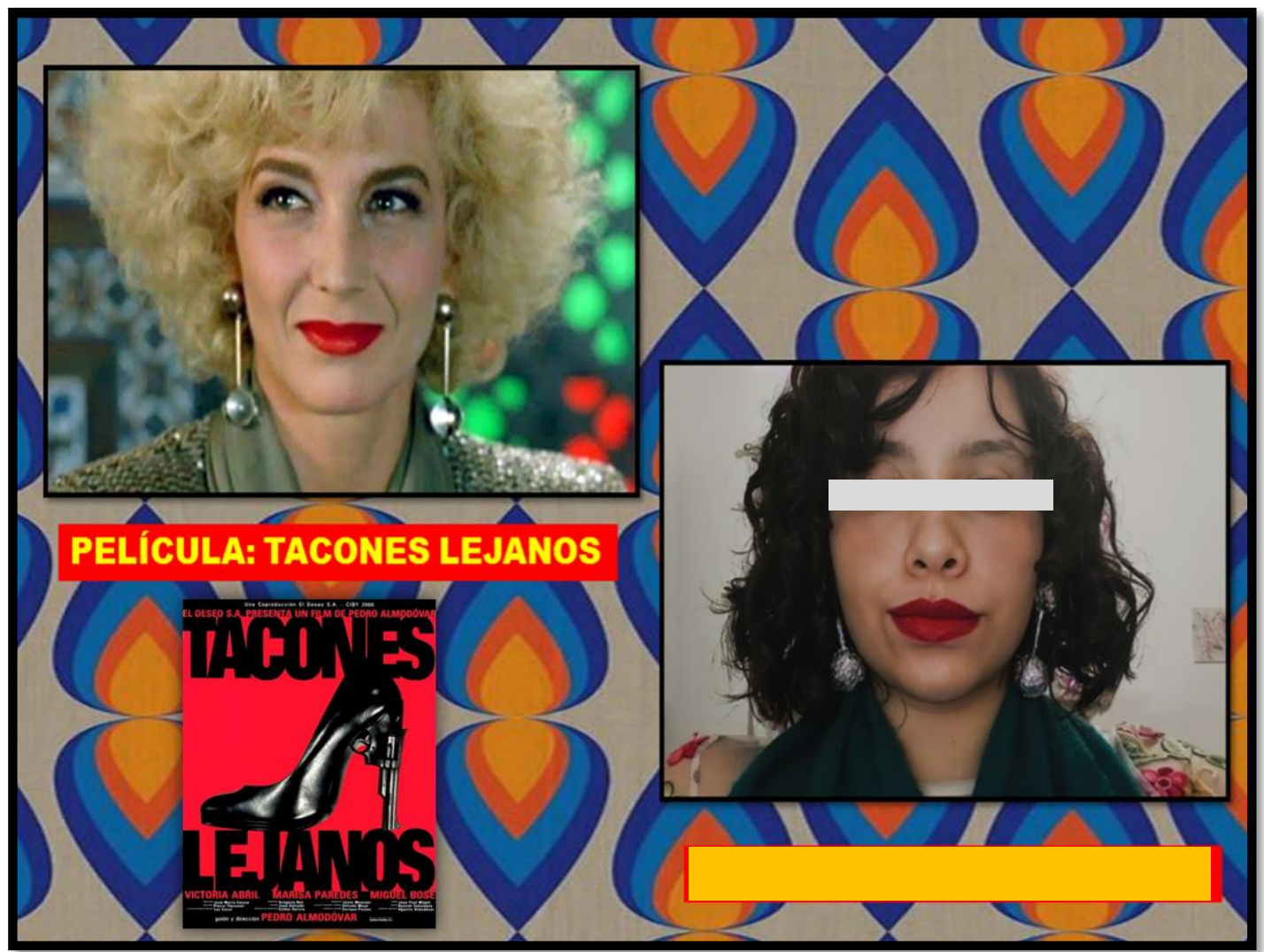

Fonte: Próprio autor. 


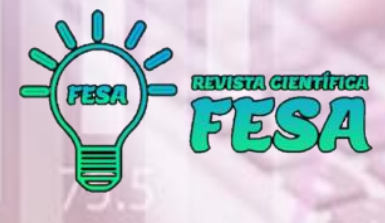

Mai. 2021

v. 1, n. $4,124-135$

ISSN: $2676-0428$

\section{Imagem 5. Carta da aluna C.S.P.S}

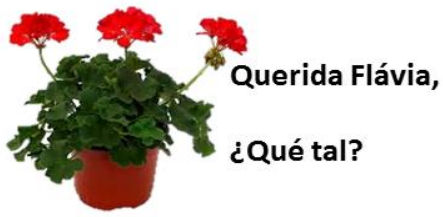

Barcelona, 16 de mayo de 2020.

Te echo mucho de menos y espero verte pronto. Como ya sabes estoy en Barcelona para un concurso de recreación de fografías en películas de Pedro Almodóvar. ¡Estoy viviendo un sueño! Quiero que sepas que Barcelona es una ciudad encantadora, he visitado muchos puntos turísticos, como la obra del Temple Expiatori de La Sagrada Familia creada por Antoni Gaudí en 1883, que es uno de sus mayores logros. Una construcción suntuosa que está en obras hasta el día de hoy, siendo la previsión de entrega para 2026.

También visité el edificio creado por Gaudí, la Pedrera entre 1906 y 1912, considerada la más importante obra local después de la Sagrada Familia. Está hecho de piedras naturales y fue planeado de manera que todas las habitaciones recibieran luz natural.

Pero lo que más me gustó fue el Museo Picasso, el museo está todo dedicado a los trabajos del maestro Pablo Ruiz Picasso - entre ellos la serie Las Meninas, de 1957. Varias de estas obras, la mayoría data del inicio de la carrera del artista, muestran una relación íntima entre Picasso y la capital de Cataluña, algo que comenzó en la juventud y perduró hasta la muerte del pintor.

La foto que participará en el concurso es de la película "Dolor y Glória", me gustaría saber si te gusta la foto.

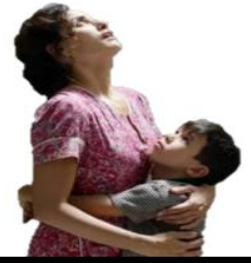

¡Un fuertísimo abrazo y adiós!

camíla.

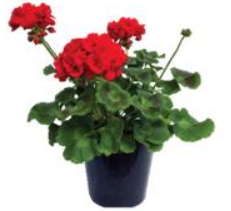

Fonte: Arquivo Pessoal.

Imagem 6. Releitura da atriz Penélope Cruz, no filme Dolor y Glória.

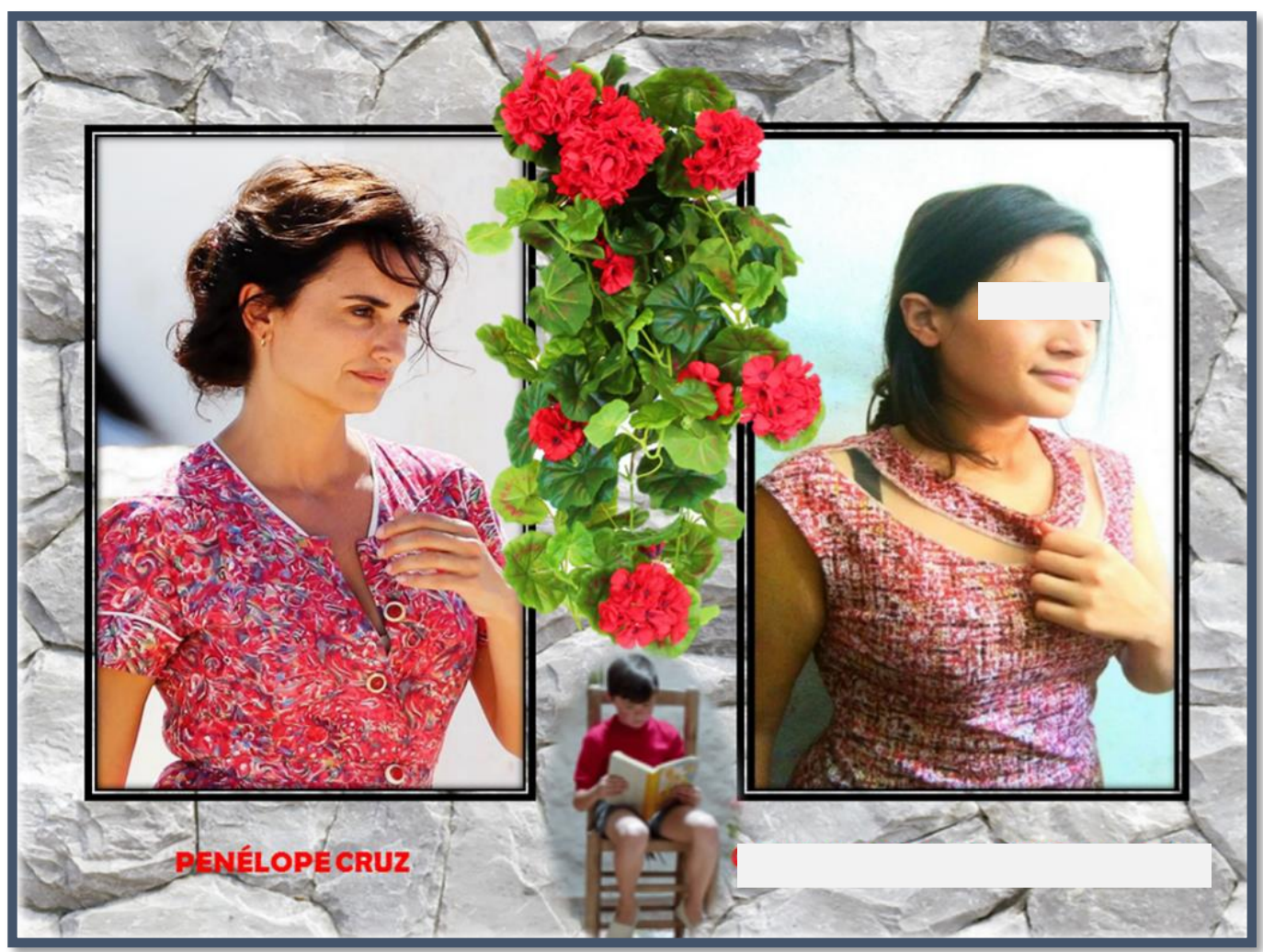

Fonte: Arquivo Pessoal. 


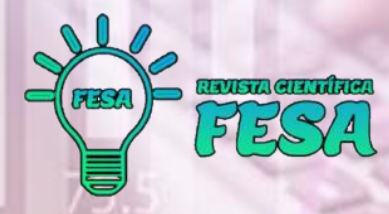

Imagem 7. M. E. F. B., releitura de Pedro Almodóvar.

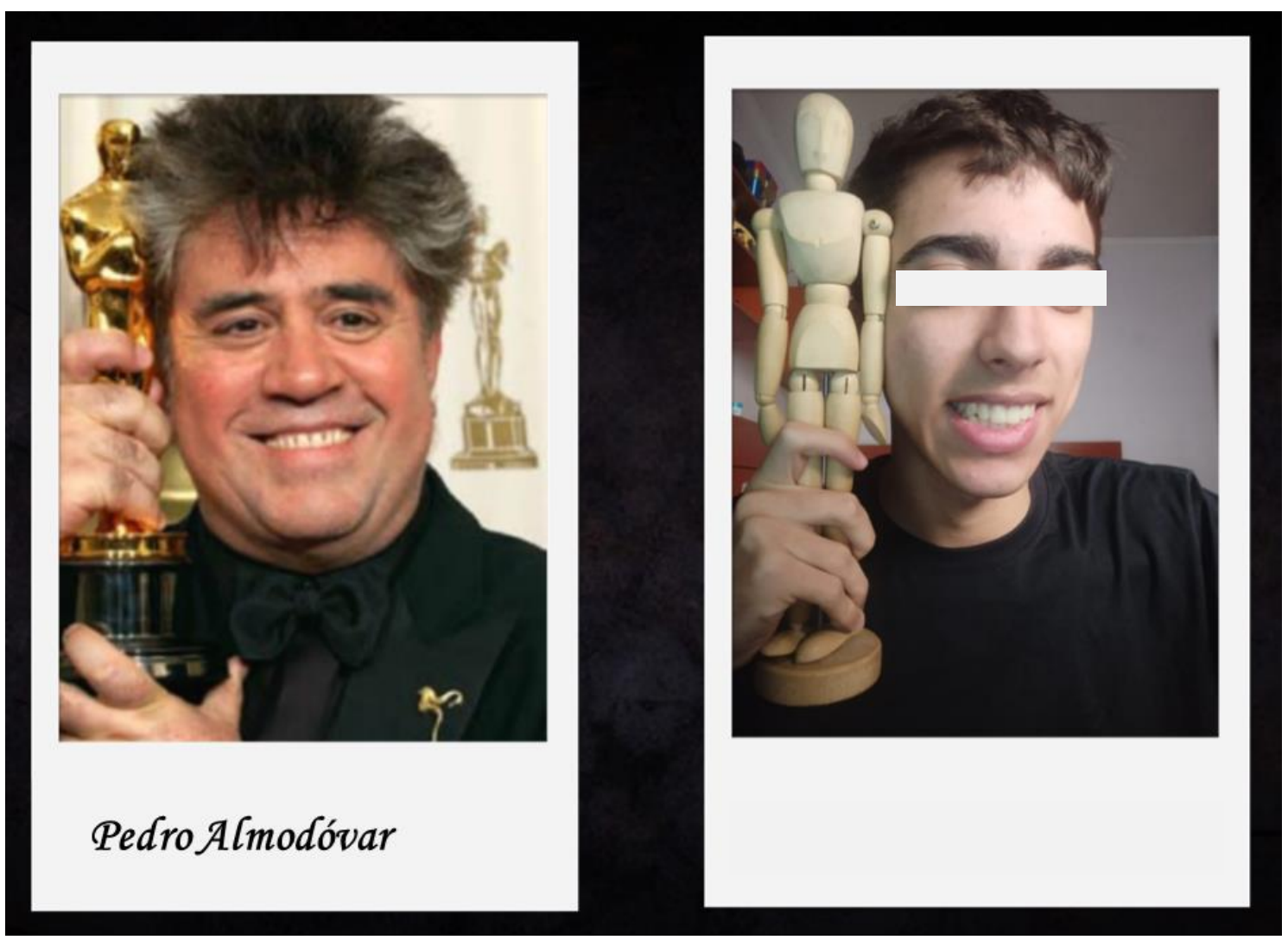

Fonte: Arquivo Pessoal.

\section{A IMPORTÂNCIA DA FORMAÇÃO E CAPACITAÇÃO DOS PROFESSORES PARA TRABALHAR COM CRIATIVIDADE NAS AULAS DE LÍNGUA ESTRANGEIRA}

Com a chegada da pandemia do vírus COVID-19, a evasão escolar e a falta de interesse dos estudantes pelo modelo de ensino remoto cresceram. O mundo mudou, a vida das pessoas mudou e, infelizmente, muitas crianças e adolescentes abandonam os estudos, alguns pela falta de acesso e outros pelo desinteresse no método utilizado nas aulas virtuais. Nesse novo contexto, 0 professor de língua estrangeira precisa se capacitar e buscar novas metodologias que estimulem a criatividade, o pensamento crítico e a imaginação dos estudantes.

Quando pensamos em uma educação relevante temos que ter a consciência das novas exigências da sociedade que clama por um ensino de qualidade com práticas inovadoras que preparem os alunos para o verdadeiro exercício da cidadania. 


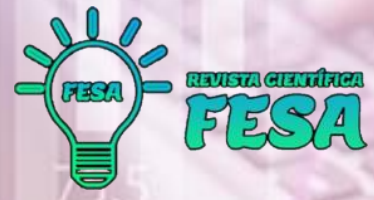

As aulas virtuais de língua estrangeira no ensino médio e médio técnico, não devem se apegar apenas aos conteúdos do livro didático como conjugação de verbos e formação de frases. O educador precisa inovar, e para isso, precisa estar comprometido com a sua prática pedagógica e levar aprendizagem de maneira dinâmica a cada aluno, visto que, com essa prática, estimula habilidades diferentes, fazendo com que o conhecimento seja melhor assimilado e possa realmente ser fixado.

A docência precisa ser estimulada e fomentada no seio da escola, e lembrar que o professor não é só um formador de alunos, mas também um formador de si mesmo e antes de tudo, ele precisa trabalhar com a sua capacitação e sua formação.

Segundo o pedagogo Paulo Freire, não há docência sem discência, ou seja, antes de ensinar o professor precisa ser aluno e reconhecer que ao ensinar ele também está aprendendo e dessa forma o ensino assume uma ética mais coerente. Quando o professor trabalha a sua própria formação e luta pela educação do seu educando, significa dizer que ele está promovendo a educação em larga escala para o exercício da cidadania no Brasil.

Por meio de uma perspectiva interacionista o sistema entende que o fazer pedagógico das escolas precisa permitir que os alunos cresçam em suas capacidades para explicar e sentir o mundo que as cerca, e, ao trabalhar e exercitar o lúdico nas aulas, o professor tira o aluno da margem de onde se encontra e o leva para inserção em uma sociedade que é pura tecnologia e colabora na construção do conhecimento desses alunos.

Para melhorar a prática escolar, a formação continuada do professor também é importante, pois permite que ele esteja em constante atualização e tenham mais criatividade em sala de aula. O professor que pesquisa a sua própria prática e a formação docente contribui com uma educação que trabalha em todos os aspectos e que não foca o conhecimento apenas nos livros.

A capacitação criativa contribui na melhoria do processo de ensino dando aos professores ferramentas para dinamizar e potencializar as aulas na formação de cidadãos críticos para uma sociedade mais igualitária. Trabalha com as inteligências múltiplas do educando ( Teoria desenvolvida pelo psicólogo norte-americano Howard Gardner.) tornando mais fácil o entendimento dos conteúdos que estão sendo abordados e desperta o interesse pelo aprendizado 
contribuindo com o processo dinâmico situado em contextos reais, sociais e históricos.

\section{CONSIDERAÇÕES FINAIS}

Sabemos que no ensino presencial a integração entre discente e docente é maior, o que faz toda a diferença no processo de aprendizagem, já no ensino remoto, o professor precisa trazer o aluno para perto dele e frequentemente motivá-lo para trabalhar o conhecimento. A atividade desenvolvida com os $2^{-}$ anos do Ensino Médio e Médio Técnico, no ano de 2020 nas escolas técnicas (Etec de Mairiporã e Etec Dr. Emílio Hernandez Aguilar), permitiu afirmar que, mesmo no ensino virtual, os alunos conseguiram desenvolver uma atividade de qualidade com foco nas pesquisas, nas artes e ampliaram o domínio no idioma estrangeiro.

Com a produção das cartas e a criação de releitura fotográfica, além de aumentarem o interesse em conhecer outra cultura, podemos perceber a importância de se trabalhar de maneira prazerosa para que todos tenham uma vivencia enriquecedora, agregando experiência de aprendizagem significatica na vida dos discentes, trabalhando de maneira interdiciplinar e contextualizada com o atual momento da educação nacional, formando assim, pessoas criticas e capacitadas para se desenvolverem e atuar democraticamente no seio em que estão inseridas.

\section{REFERÊNCIAS BIBLIOGRÁFICAS}

ALMODÓVAR, Pedro. Colóquio con Pedro Almodóvar. Madrid: Filmoteca Española, 1989.

ALMODÓVAR, Pedro. En la Ser. YouTube, 7 de março de 2013. Disponível em: https://www.youtube.com/watch?v=iBEV21eYhh8. Acesso em: 11 ago. 2014.

ALMODÓVAR, Pedro. Mulheres à beira de um ataque de nervos (Mujeres al borde de un ataque de nervios). Direção: Pedro Almodóvar. Produção: Esther García. El Deseo S. A: Madri, 1988.

ALMODÓVAR, Pedro. Tudo sobre minha mãe (Todo sobre mi madre). Direção: Pedro Almodóvar. Produção: Esther García. El Deseo S. A./Pathé: Madri, 1999. 
ALMODÓVAR, Pedro. VOLVER. Produção: Esther García. El Deseo S.A.: Madri, 2006.

ARNHEIM, R. A arte do cinema. Edições 70: Lisboa, 1989.

EVANGELISTA, Bruno. Projetos Culturais nas Aulas de Língua Espanhola. Etec: São Paulo, 2020.

STRAUSS, Frederic. Conversas com Almodóvar. Jorge Zahar Editor Ltda: Rio de Janeiro, 2008. 